\title{
Ex Vivo Assessment and Validation of Water Exchange Performance of 23 Heat and Moisture Exchangers for Laryngectomized Patients
}

\author{
Cindy van den Boer MD, Sara H Muller PhD, Andrew D Vincent PhD, \\ Michiel WM van den Brekel MD PhD, and Frans JM Hilgers MD PhD
}

\begin{abstract}
BACKGROUND: Breathing through a tracheostoma results in insufficient warming and humidification of the inspired air. This loss of air conditioning, especially humidification, can be partially restored with the application of a heat and moisture exchanger (HME) over the tracheostoma. For medical professionals, it is not easy to judge differences in water exchange performance of various HMEs owing to the lack of universal outcome measures. This study has three aims: assessment of the water exchange performance of commercially available HMEs for laryngectomized patients, validation of these results with absolute humidity outcomes, and assessment of the role of hygroscopic salt present in some of the tested HMEs. METHODS: Measurements of weight and absolute humidity at end inspiration and end expiration at different breathing volumes of a healthy volunteer were performed using a microbalance and humidity sensor. Twenty-three HMEs from 6 different manufacturers were tested. Associations were determined between core weight, weight change, breathing volume, and absolute humidity, using both linear and nonlinear mixed effects models. RESULTS: Water exchange of the 23 HMEs at a breathing volume of $0.5 \mathrm{~L}$ varies between 0.5 and $3.6 \mathrm{mg}$. Both water exchange and wet core weight correlate strongly with the end-inspiratory absolute humidity values $\left(r^{2}=0.89 / 0.87\right)$. Hygroscopic salt increases core weight. CONCLUSIONS: The 23 tested HMEs for laryngectomized patients show wide variation in water exchange performance. Water exchange correlates well with the end-inspiratory absolute humidity outcome, which validates the ex vivo weight change method. Wet core weight is a predictor of HME performance. Hygroscopic salt increases the weight of the core material. The results of this study can help medical professionals to obtain a more founded opinion about the performance of available HMEs for pulmonary rehabilitation in laryngectomized patients, and allow them to make an informed decision about which HME type to use. Key words: total laryngectomy; heat and moisture exchanger; HME; comparison study; water exchange; humidity; weight; quality of life. [Respir Care 2014;59(8):1161-1171. (C) 2014 Daedalus Enterprises]
\end{abstract}

\section{Introduction}

After total laryngectomy, breathing through the nose is inevitably replaced by breathing through the permanent

\footnotetext{
Drs van den Boer, van den Brekel, and Hilgers are affiliated with the Department of Head and Neck Oncology and Surgery, Dr Muller is affiliated with the Department of Clinical Physics and Instrumentation, and Dr Vincent is affiliated with the Department of Biometrics, Netherlands Cancer Institute-Antoni van Leeuwenhoek; Drs van den Brekel and Hilgers are also affiliated with the Institute of Phonetic Sciences, University of Amsterdam; Dr van den Brekel is also affiliated with the Department of Maxillofacial Surgery, Academic Medical Center, University of Amsterdam, Amsterdam, The Netherlands
}

tracheostoma, whereby inspired air is no longer optimally conditioned before reaching the trachea. The colder and dryer inspired air leads to pulmonary complaints such as increased mucus production and excessive coughing, and

\footnotetext{
Supplementary material related to this paper is available at http:// www.rcjournal.com.

This research was funded in part by an unrestricted research grant of the manufacturer of some of the tested HMEs, Atos Medical. The study sponsor had no involvement in the study design; in the collection, analysis, and interpretation of data; in the writing of the manuscript; or in the decision to submit the manuscript for publication. The authors have disclosed no other conflicts of interest.
} 
causes frequent airway infections. ${ }^{1}$ For pulmonary rehabilitation after total laryngectomy, heat and moisture exchangers (HMEs) are widely used to partially restore (this lack of) air conditioning. Patients who use these devices consistently have significantly fewer complaints of sputum production and coughing and report a better quality of life. ${ }^{2,3}$

HMEs consist of a functional core material (usually a foam, sometimes coated with hygroscopic salt) contained in a cassette. The functional core material traps and releases a small amount of water during exhalation and inhalation, respectively. With different types of HMEs currently available, the literature is growing rapidly on the effect of HMEs on clinical complaints, ${ }^{4-9}$ influence on respiratory function, ${ }^{2,10-12}$ in vivo humidity measurements, ${ }^{13-15}$ and comparison of in vitro measurements. ${ }^{16,17}$ However, no comparative data have been published as yet on the performance of the whole range of HMEs available for laryngectomized patients today. In vivo studies are not suitable for measuring a large variety of HMEs, as the measurements are too time-consuming and burdensome for patients. Furthermore, in vivo humidity measurements are technically difficult to perform..$^{13,15}$ In vitro measurements, where either a mechanical lung model according to the ISO standards (International Standard Organization ISO 9360:2000 and 2001) or hygrometry is used, would allow the reliable assessment of a wide range of HMEs when performed in the same test rig; the heat and moisture capacity of these configurations, however, are probably not fully representative of human breathing. ${ }^{18-20}$

These issues were overcome with the recent development of an ex vivo method that enables measurement of water exchange performance of a variety of HMEs within a short timeframe, without the need to trouble patients, while still being universally feasible. ${ }^{21}$ In this method, the weight of an HME is measured twice: once at the end of inspiration and once at the end of expiration. The weight difference between end inspiration and end expiration (as function of the breathing volume) represents the water exchange performance during the breathing cycle.

The present study has three aims: ex vivo assessment of the water exchange performance of commercially available HMEs for laryngectomized patients, validation of these results with absolute humidity outcomes, and assessment of the role of hygroscopic salt present in some of the HMEs tested.

\footnotetext{
Correspondence: Frans JM Hilgers MD PhD, Department of Head and Neck Oncology and Surgery, Netherlands Cancer Institute-Antoni van Leeuwenhoek, Plesmanlaan 1211066 CX Amsterdam, Netherlands. Email: f.hilgers@nki.nl.
}

DOI: $10.4187 /$ respcare. 02840

\section{QUICK LOOK}

\section{Current knowledge}

Breathing through a tracheostoma bypasses the normal heat and humidifying mechanisms of the upper airway, resulting in insufficient conditioning of the inspired air. A heat and moisture exchanger (HME) placed over the tracheostoma can increase tracheopulmonary humidity, improving patient comfort.

\section{What this paper contributes to our knowledge}

Twenty-three HMEs designed for laryngectomized patients demonstrated a wide variation in water exchange performance. The efficiency of water exchange correlated well with the end-inspiratory absolute humidity. Wet core weight proved to be a good predictor of HME performance.

\section{Methods}

The study was approved by the institutional review board of the Netherlands Cancer Institute-Antoni van Leeuwenhoek.

\section{HME Devices}

Twenty-three different commercially available HMEs intended for pulmonary rehabilitation of laryngectomized patients were ordered via local distributors. In vitro HME water loss and pressure drop values (ISO standards) ${ }^{18,19}$ were available for HMEs produced by two manufacturers. The other manufacturers, who were all approached for sharing the ISO standard values for their various HMEs, were unwilling or unable to provide these data. The available manufacturer details of the HMEs tested are shown in Table 1.

Most HMEs consisted of a core material and a relatively simple cassette. Some HMEs had a more elaborate cassette design potentially increasing HME performance with additional water storage: the four hands-free HMEs; the Provox Micron (Atos Medical, West Allis, Wisconsin), which has an additional electrostatic filter that, although hydrophobic, influences HME performance by preheating the inhaled air ${ }^{22}$; the Cyranose HME (Ceredas, Antony, France), which contains a metallic grid; and the BlomSinger humidifier holder (InHealth Technologies, Carpinteria, California), which has a considerably larger cassette.

\section{Water Exchange and Humidity Measurements}

Water exchange (weight changes between inhalation and exhalation and vice versa), end-inspiratory absolute hu- 
Table 1. Manufacturer Information for the 23 Tested HMEs

\begin{tabular}{|c|c|c|c|c|c|}
\hline Brand & HME Type & $\begin{array}{l}\text { Hands-Free } \\
\text { Speech }\end{array}$ & Core Material & $\begin{array}{c}\text { Case } \\
\text { Material }\end{array}$ & $\begin{array}{c}\text { ISO Water Loss } \\
(\mathrm{mg} / \mathrm{L})^{* \dagger}\end{array}$ \\
\hline \multirow[t]{3}{*}{ Blom-Singer } & Blom-Singer HME system & No & Foam impregnated with salt + antibacterial agent & Plastic & NA \\
\hline & Blom-Singer humidifier holder $\ddagger$ & No & Foam impregnated with salt + antibacterial agent & Plastic & NA \\
\hline & Blom-Singer hands-free valve & Yes & Foam impregnated with salt + antibacterial agent & Plastic & NA \\
\hline Cyranose & Cyranose HME $\ddagger$ & No & Open cell polyester-based polyurethane foam & Aluminum & NA \\
\hline \multirow[t]{7}{*}{ Kapitex } & Trachi-Naze Blue & No & Pre-filter + activated carbon + HME layer & Plastic & NA \\
\hline & Trachi-Naze Green & No & Pre-filter + activated carbon + HME layer & Plastic & NA \\
\hline & Trachi-Naze Orange & No & Pre-filter + activated carbon + HME layer & Plastic & NA \\
\hline & Trachi-Naze Plus Blue & No & Pre-filter + activated carbon + HME layer & Plastic & NA \\
\hline & Trachi-Naze Plus Green & No & Pre-filter + activated carbon + HME layer & Plastic & NA \\
\hline & Trachi-Naze Plus Orange & No & Pre-filter + activated carbon + HME layer & Plastic & NA \\
\hline & Trachi-Naze hands-free valve type B§ & Yes & Pre-filter + activated carbon + HME layer & Plastic & NA \\
\hline \multirow[t]{5}{*}{ Heimomed } & Prim-Air Phon II & No & Foam impregnated with salt & Plastic & $17.1-23.3 \dagger$ \\
\hline & Prim-Air Phon II high flow & No & Foam impregnated with salt & Plastic & NA \\
\hline & Prim-Air Phon I & No & Foam impregnated with salt & Plastic & $23.2-24.6 \dagger$ \\
\hline & Prim-Air Phon I high flow & No & Foam impregnated with salt & Plastic & NA \\
\hline & Prim-Air hands-free & Yes & Foam impregnated with salt & Plastic & NA \\
\hline \multirow[t]{6}{*}{ Atos Medical } & Provox Micron $\ddagger$ & No & Foam impregnated with $\mathrm{CaCl}+$ electrostatic filter & Plastic & $26^{*}$ \\
\hline & Provox Normal & No & Foam impregnated with $\mathrm{CaCl}$ & Plastic & $23.7 *$ \\
\hline & Provox HiFlow & No & Foam impregnated with $\mathrm{CaCl}$ & Plastic & $25.4^{*}$ \\
\hline & Provox Xtra Moist & No & Foam impregnated with $\mathrm{CaCl}$ & Plastic & $21.5^{*}$ \\
\hline & Provox Xtra Flow & No & Foam impregnated with $\mathrm{CaCl}$ & Plastic & $24 *$ \\
\hline & Provox hands-free & Yes & Foam impregnated with $\mathrm{CaCl}$ & Plastic & $19.1^{*}$ \\
\hline Servona & Servox HME & No & Foam impregnated with salt & Plastic & NA \\
\hline \multicolumn{6}{|c|}{ 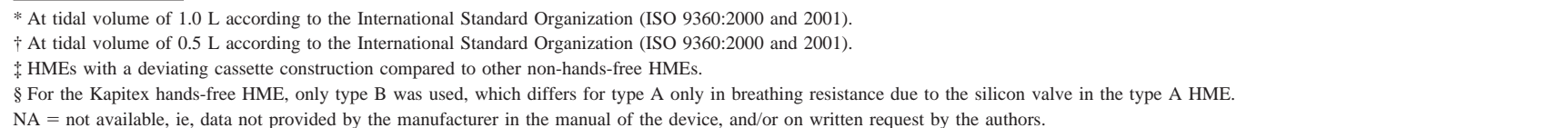 } \\
\hline
\end{tabular}

midity $\left(\mathrm{AH}_{\mathrm{insp}}\right)$, and breathing volume were measured using ex vivo weighing as described previously. ${ }^{21}$ In the test configuration (Fig. 1), the HME was mounted on a T-tube containing a fast heated capacitive hygrometer, absolute humidity sensor with a response time of $0.1-0.2 \mathrm{~s},{ }^{23}$ and a spirometer (MLT300 Flowhead, ADInstruments, Oxfordshire, United Kingdom). A healthy volunteer (first author, $\mathrm{CvdB}$ ) breathed through the spirometer. The maximum flow of the spirometer was $300 \mathrm{~L} / \mathrm{min}$, so the volunteer was instructed to breathe at normal speed; in case of doubt, the flow signal could be inspected. For the weight measurements, a microbalance (MC210P, Sartorius, Göttingen, Germany; accuracy within $0.1 \mathrm{mg}$ ) was used. Before the start of weight measurements, each HME was prepared by the volunteer breathing through the HME until equilibrium of water saturation was reached. The length of this conditioning period varied between the different HMEs and was determined for each HME separately. HME weight measurements were performed 25 times, alternating at the end of inspiration and at the end of expiration, using three different breathing patterns (tidal, shallow, and deep breathing). Between each weight measurement, at least five breathing cycles (at tidal volume) were performed to re-

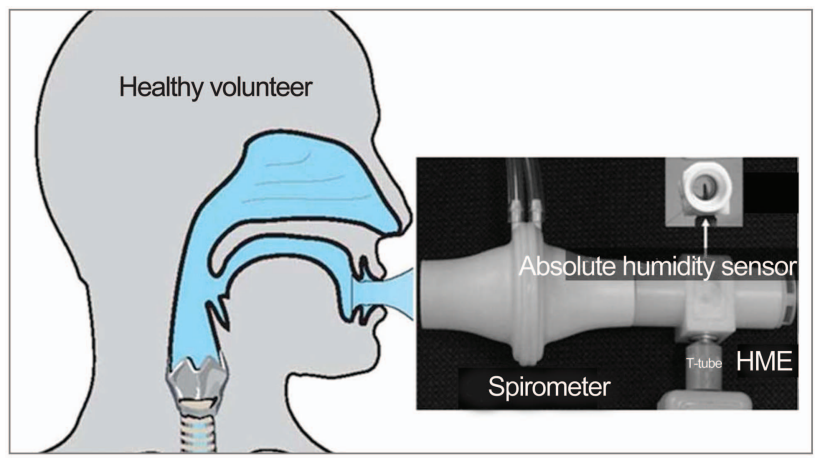

Fig. 1. Test configuration. The healthy volunteer breathes through the spirometer (dead space $70 \mathrm{~mL}$ ), which is connected to a Tshaped tube (dead space $30 \mathrm{~mL}$ ) containing an absolute humidity sensor. At the end of this T-tube, the heat and moisture exchanger (HME) is connected (right side). For optimal connection to the test configuration tube, a small connector tube was handmade for all different HME sizes.

condition the HME. Of each HME type, 3 different HMEs were measured on separate days. The $23 \mathrm{HME}$ types were measured in a randomized order. The first weight change was discarded as a result of the differing conditioning 
periods as well as the weight change between different breathing patterns, resulting in 21 weight changes for analysis per HME. Weight data points deviating $>75 \%$ from the previous and following weights in the data sequence were considered outliers and therefore excluded.

\section{Core Weight and Water Uptake in Humid Conditions}

In addition to the ex vivo weighing method, weighing of the core material of the HMEs themselves in different air humidity conditions was carried out to assess the amount of water accumulated in the devices, identical to the method described in 1988 by Ploysongsang et al. ${ }^{24}$ The weights of the HME core material were measured after conditioning in completely dry air and at different higher air humidity conditions up until approximately 55\% relative humidity $(\mathrm{RH})$ at $21^{\circ} \mathrm{C}$. Higher levels of humidity were not used, to avoid nonlinear behavior in the hygroscopic HMEs. ${ }^{25}$ HMEs were kept in room conditions (between 30\% and $40 \% \mathrm{RH}$ ), and long storage or storage at high humidity levels was avoided to prevent plastics of cassette and core material from slowly (time scale, days) absorbing water and getting heavier.

The HMEs were placed in each condition for approximately $4 \mathrm{~h}$ before being weighed. For each HME, the weight increase gradient (weight increase with increasing RH: mg/\% RH) was calculated from the HME weight increase as a function of RH. Weights of the core material were obtained by dismantling the HME and subtracting cassette weight. Dry core weight is the core weight at $0 \%$ $\mathrm{RH}$. Wet core weight is the core weight of HME under operating conditions (see conditioning above). The mean outcome of 3 HMEs per type was used for analysis.

\section{Additional Equipment}

HMEs were placed in an airtight box during weight measurement to prevent water evaporation. A freeze drying chamber (FDC206, SpeedVac system, Savant Instruments, Farmingdale, New York) was used to create a vacuum for $0 \% \mathrm{RH}$ conditioning. For the wet conditions, a Plexiglas climate room containing a electromotor-driven propeller for air mixture $\left(26 \times 42 \times 16 \mathrm{~cm}^{2}\right.$ as described previously by Zuur et al) ${ }^{15}$ was used. Room conditions were recorded during the measurements, using a commercial calibrated humidity sensor (Testo, Almere, Netherlands) with an accuracy of $\pm 0.6^{\circ} \mathrm{C}$ and $\pm 2.5 \%$ RH. Calibration of the absolute humidity sensor was performed as described previously, ${ }^{15}$ using the Testo sensor as reference humidity sensor. Calibration of the spirometer was performed according to the recommendations of the manufacturer. Spirometer data were recorded and analyzed with Powerlab software (ADInstruments), and humidity values were registered with data acquisition software (Acquis 2.8, Anästhesie-Technik, Göttingen, Germany) and exported to a spreadsheet (Excel, Microsoft, Redmond, Washington). The body temperature of the healthy volunteer was checked at every ex vivo measurement with an electronic aural thermometer (Genius2, Kendall, Tyco Healthcare Group, Mansfield, Ohio).

\section{Data Normalization and Statistical Analysis}

Weight changes and $\mathrm{AH}_{\text {insp }}$ data were normalized to a reference ambient humidity of $5 \mathrm{mg} / \mathrm{L}$ as described previously. ${ }^{21} \mathrm{~A}$ summary of the normalization formulas is given in Appendix 1 (see the supplementary materials at http:// www.rcjournal.com).

Assessment of the association between water exchange and average breathing volume was determined using a linear mixed effects model for each HME type (three HMEs of one type together). The association between $\mathrm{AH}_{\mathrm{insp}}$ and inspiratory breathing volume was determined using an exponential decay nonlinear least squares regression as described previously. ${ }^{21}$

For the core weight experiments, weighted $r^{2}$ values were calculated using weighted Pearson correlations with inverse variances as weights. Aikake information criterion was used to compare the associations between inspirational absolute humidity and both wet and dry core weights in two weighted linear regressions.

\section{Results}

The water exchange (weight change between inhalation and exhalation) as a function of the breathing volume for all HMEs is shown in Figure 2. The graphs represent the exchange of water that was condensed onto and evaporated from the HME during respiration per HME type. Of the total weight change data points $(1,449), 21(1.4 \%)$ points were excluded as outliers according to the criterion given in the methods section. The parameters of the model fits shown in Figure 2 are supplied in Appendix 2 (see the supplementary materials at http://www.rcjournal.com). Ambient absolute humidity during the measurements ranged between 7-12 mg/L, and averages and SD per HME type are given in Appendix 2 in Table 5 (see the supplementary materials).

A breathing volume of $0.5 \mathrm{~L}$ was chosen for comparison between the HMEs (vertical dashed line, Fig. 2), because this is the average tidal breathing volume previously reported for laryngectomized patients. ${ }^{12}$ For each of the tested HMEs, the water exchange at the breathing volume of $0.5 \mathrm{~L}$ can be found in Table 2 . The water exchange capacity ranged from 0.5 to $3.6 \mathrm{mg}$. Most HME types had a standard error of about 0.1 , but the standard error of the hands-free HMEs tended to be slightly larger (up to 0.16). 

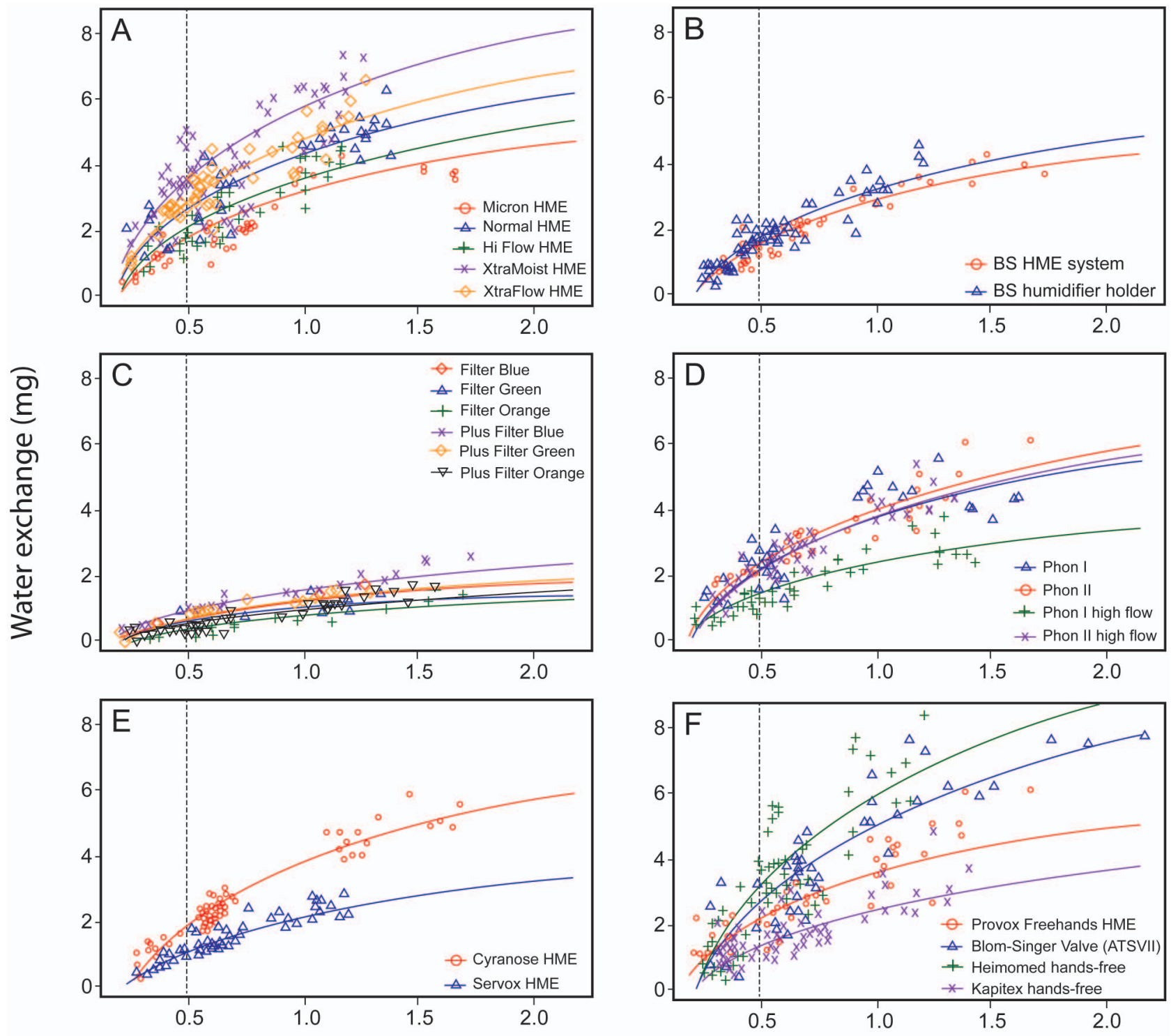

\section{Breathing volume (L)}

Fig. 2. The observed (points) and estimated (lines) association between breathing volume and water exchange (weight change between inspiration and expiration) for different heat and moisture exchangers (HMEs), normalized to the chosen reference ambient humidity of $5 \mathrm{mg} / \mathrm{L} .{ }^{21}$ Per HME type, 63 data points were analyzed (21 per HME). HMEs are categorized per brand, and the hands-free HMEs are plotted separately. The four HMEs with hands-free speech are placed together as a separate group (panel F) because these HMEs are only used by a selected group of laryngectomized patients, whereas the other HMEs are useful for all laryngectomized individuals irrespective of their voice rehabilitation method. Vertical dashed lines show the average tidal breathing volume for laryngectomized patients used to compare HMEs.

Figure 3A presents an overview of all HME performances from Table 2 for the water exchange including the standard errors (vertical bars) ranked from high to low performance.

In Table 2, the values of $\mathrm{AH}_{\text {insp }}$ at a breathing volume of $0.5 \mathrm{~L}$ are reported. Details of the measurements of $\mathrm{AH}_{\mathrm{insp}}$ and the parameters of the exponential decay model ${ }^{21}$ are given in Appendix 2, Table 4 (see the supplementary ma- terials at http://www.rcjournal.com). Figure 3B shows the HME performances ranked according to $\mathrm{AH}_{\text {insp }}$.

The correlation between water exchange and $\mathrm{AH}_{\text {insp }}$ values for each HME tested is shown in Figure 4. The calculated inverse variance weighted $\mathrm{r}^{2}$ is 0.89 . See Table 5 and Fig. 9 in the supplementary material for an in-depth analysis of the correlation shown with a Bland-Altman plot. 


\section{Assessment of HMEs for Patients With LaRyngectomy}

Table 2. Model Estimate of Water Exchange Values and $\mathrm{AH}_{\text {insp }}$ at Volumes of $0.5 \mathrm{~L}$ and Standardized to a Reference Ambient Humidity of 5 $\mathrm{mg} / \mathrm{L}$

\begin{tabular}{|c|c|c|c|c|c|c|}
\hline HME Type & $\begin{array}{c}\text { Water } \\
\text { Exchange } \\
(\mathrm{mg})^{*}\end{array}$ & $\begin{array}{l}\mathrm{AH}_{\text {insp }} \\
(\mathrm{mg} / \mathrm{L})^{*}\end{array}$ & $\begin{array}{c}\text { Weight Increase } \\
\text { Gradient } \\
\text { (mg/\% RH) }\end{array}$ & $\begin{array}{l}\text { Dry Core } \\
\text { Weight } \\
(\mathrm{mg}) \dagger\end{array}$ & $\begin{array}{c}\text { Wet Core } \\
\text { Weight } \\
(\mathrm{mg}) \dagger\end{array}$ & $\begin{array}{c}\text { Water } \\
\text { Uptake } \\
\mathrm{mg} \pm \mathrm{SD}\end{array}$ \\
\hline Blom-Singer HME system & $1.54 \pm 0.10$ & $7.59 \pm 0.19$ & 0.25 & $56.6 \pm 3.8$ & $73.8 \pm 5.3$ & $17.3 \pm 1.9$ \\
\hline Blom-Singer humidifier holder & $1.65 \pm 0.10$ & $7.78 \pm 0.16$ & 0.71 & $126.8 \pm 2.3$ & $191.8 \pm 4.4$ & $65.0 \pm 0.8$ \\
\hline Blom-Singer hands-free valve & $2.48 \pm 0.16$ & $10.87 \pm 0.22$ & 0.71 & $126.8 \pm 2.3$ & $191.8 \pm 4.4$ & $65.0 \pm 0.8$ \\
\hline Cyranose HME & $1.94 \pm 0.10$ & $8.30 \pm 0.31$ & 0.02 & $137.2 \pm 6.0$ & $138.7 \pm 5.4$ & $1.5 \pm 0.1$ \\
\hline Trachi-Naze Filter Blue§ & $0.78 \pm 0.09$ & $5.93 \pm 0.22$ & 0.08 & $44.4 \pm 3.4$ & $50.5 \pm 5.0$ & $6.1 \pm 4.7$ \\
\hline Trachi-Naze Filter Green & $0.63 \pm 0.09$ & $5.80 \pm 0.17$ & 0.14 & $45.9 \pm 3.8$ & $55.2 \pm 4.4$ & $9.3 \pm 0.6$ \\
\hline Trachi-Naze Filter Orange & $0.45 \pm 0.09$ & $5.45 \pm 0.23$ & 0.10 & $50.5 \pm 3.8$ & $57.1 \pm 4.2$ & $6.6 \pm 0.8$ \\
\hline Trachi-Naze Plus Blue & $0.92 \pm 0.09$ & $6.02 \pm 0.22$ & 0.12 & $46.4 \pm 4.9$ & $54.4 \pm 6.3$ & $8.0 \pm 1.7$ \\
\hline Trachi-Naze Plus Green & $0.68 \pm 0.09$ & $6.01 \pm 0.24$ & 0.07 & $43.9 \pm 4.1$ & $49.0 \pm 2.5$ & $5.1 \pm 1.7$ \\
\hline Trachi-Naze Plus Orange & $0.56 \pm 0.09$ & $5.83 \pm 0.17$ & 0.08 & $55.2 \pm 4.4$ & $60.5 \pm 4.7$ & $5.3 \pm 0.3$ \\
\hline Trachi-Naze hands-free $\S$ & $1.29 \pm 0.11$ & $6.68 \pm 0.12$ & 0.08 & $44.4 \pm 3.4$ & $50.5 \pm 5.0$ & $6.1 \pm 4.7$ \\
\hline Prim-Air Phon II & $2.09 \pm 0.11$ & $8.78 \pm 0.20$ & 0.16 & $143.6 \pm 2.7$ & $160.0 \pm 5.9$ & $16.4 \pm 4.6$ \\
\hline Prim-Air Phon II high flow & $2.03 \pm 0.12$ & $10.45 \pm 0.14$ & 0.34 & $179.5 \pm 10.0$ & $213.2 \pm 16.9$ & $33.8 \pm 7.1$ \\
\hline Prim-Air Phon I & $2.16 \pm 0.10$ & $7.33 \pm 0.22$ & 0.20 & $97.5 \pm 2.8$ & $117.7 \pm 5.6$ & $20.2 \pm 2.8$ \\
\hline Prim-Air Phon I high flow & $1.36 \pm 0.09$ & $6.28 \pm 0.27$ & 0.06 & $71.0 \pm 15.3$ & $75.3 \pm 11.5$ & $4.4 \pm 5.5$ \\
\hline Prim-Air hands-free & $2.98 \pm 0.16$ & $13.35 \pm 0.22$ & 0.51 & $166.3 \pm 16.2$ & $215.0 \pm 20.8$ & $48.7 \pm 6.3$ \\
\hline Provox Micron HME & $1.86 \pm 0.11$ & $7.56 \pm 0.27$ & 0.25 & $86.6 \pm 6.3$ & $106.6 \pm 7.4$ & $19.9 \pm 3.0$ \\
\hline Provox Normal HME & $2.66 \pm 0.13$ & $8.53 \pm 0.13$ & 0.62 & $88.8 \pm 6.5$ & $141.9 \pm 11.3$ & $53.1 \pm 8.4$ \\
\hline Provox HiFlow HME & $2.04 \pm 0.11$ & $7.91 \pm 0.19$ & 0.60 & $89.4 \pm 5.3$ & $137.1 \pm 9.7$ & $47.7 \pm 4.5$ \\
\hline Provox XtraMoist HME & $3.61 \pm 0.13$ & $11.91 \pm 0.22$ & 1.72 & $173.4 \pm 5.5$ & $345.9 \pm 33.2$ & $172.5 \pm 28.5$ \\
\hline Provox XtraFlow HME & $2.89 \pm 0.11$ & $10.21 \pm 0.16$ & 0.99 & $159.8 \pm 4.7$ & $249.0 \pm 15.4$ & $89.2 \pm 11.0$ \\
\hline Provox hands-free HME & $2.15 \pm 0.12$ & $8.08 \pm 0.22$ & 0.37 & $103.3 \pm 15.8$ & $134.6 \pm 18.0$ & $31.3 \pm 0.9$ \\
\hline Servox HME & $1.14 \pm 0.10$ & $7.14 \pm 0.13$ & 0.07 & $91.3 \pm 1.5$ & $95.9 \pm 1.7$ & $4.6 \pm 0.2$ \\
\hline \multicolumn{7}{|c|}{$\begin{array}{l}\text { * Mean } \pm \text { SE. } \\
\dagger \text { Mean } \pm \text { SD. } \\
¥ \text { Core material identical, so weight increase gradient and other values were only measured once. } \\
\S \text { Core material identical, so weight increase gradient and other values were only measured once. } \\
\mathrm{AH}_{\text {insp }}=\text { end-inspiratory absolute humidity } \\
\mathrm{RH}=\text { relative humidity } \\
\mathrm{HME}=\text { heat and moisture exchanger }\end{array}$} \\
\hline
\end{tabular}

The last 4 columns of Table 2 list the results for the weight measurements of the HMEs in different humidities: the weight increase gradient (weight increase per \% $\mathrm{RH}$ ), dry core weight, wet core weight, and water uptake (the difference between wet and dry core weight). The correlations between $\mathrm{AH}_{\text {insp }}$ and wet core weight are shown in Figure 5 for all HMEs, as well as for a selection of HMEs with relatively simple cassettes that are likely to have no relevant HME effect of their own (see selected HMEs in methods section). The overall weighted variance $r^{2}$ was 0.79 , and 0.87 for the simple cassette HMEs. The correlations between $\mathrm{AH}_{\text {insp }}$ and dry core weights for all HMEs and the simple cassette HMEs were 0.69 and 0.85 , respectively. The Aikake information criterion of the weighted linear regressions of $\mathrm{AH}_{\text {insp }}$ as predicted by wet core weight was 29.9, whereas the Aikake information criterion when using dry core weight was 38.0, suggesting that wet weight is a better predictor of $\mathrm{AH}_{\text {insp. }}$. Water exchange also correlates with core weight (see Table 2), but the $r^{2}$ values are lower because of the larger standard error of the water exchange values.

The relation between HME water uptake and water exchange values is illustrated in Figure 6 for the simple cassette HMEs. The data points for the HMEs with a hygroscopic (salt-containing) core material and the types specified by the manufacturer as not containing such material are marked differently (see Table 1 for details). It is clear that, for hygroscopic HMEs, the water exchange improves when more water is absorbed onto the HME.

\section{Discussion}

In this study, the ex vivo water exchange performance of 23 presently obtainable HMEs was assessed, the results of which were then validated with absolute humidity measurements at the end of inspiration $\left(\mathrm{AH}_{\mathrm{insp}}\right)$.

Most strikingly, the performance of the various devices proved to be highly heterogeneous. The HME water ex- 

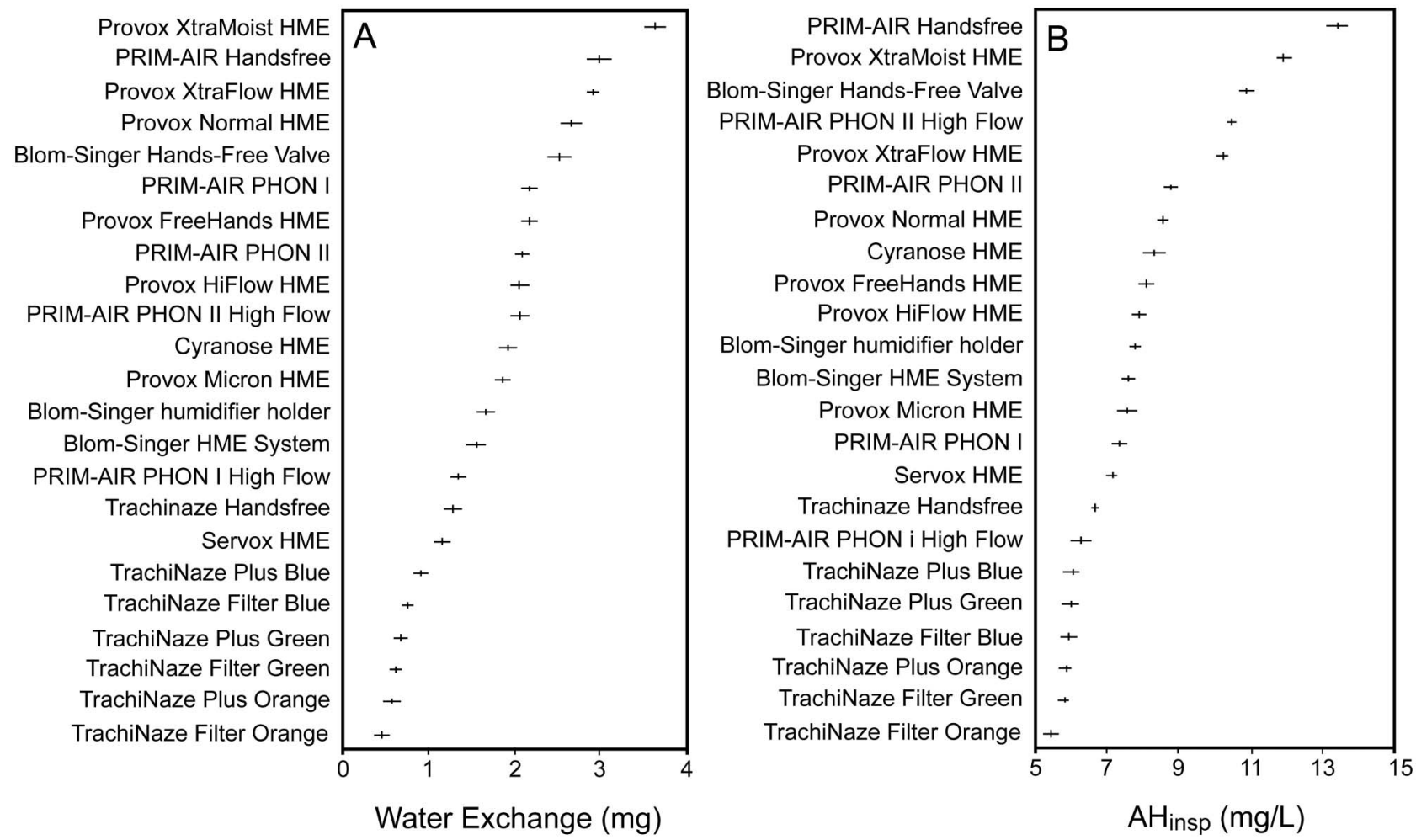

Fig. 3. Mean water exchange values $(A)$ and end-inspiratory humidity $\left(A H_{i n s p}\right)$ values $(B)$ ranked at performance from high to low at a breathing volume $0.5 \mathrm{~L}$ and normalized to a reference ambient humidity of $5 \mathrm{mg} / \mathrm{L}$ (data shown in Table 2). Horizontal lines through each point represent the standard error. $\mathrm{HME}=$ heat and moisture exchanger.

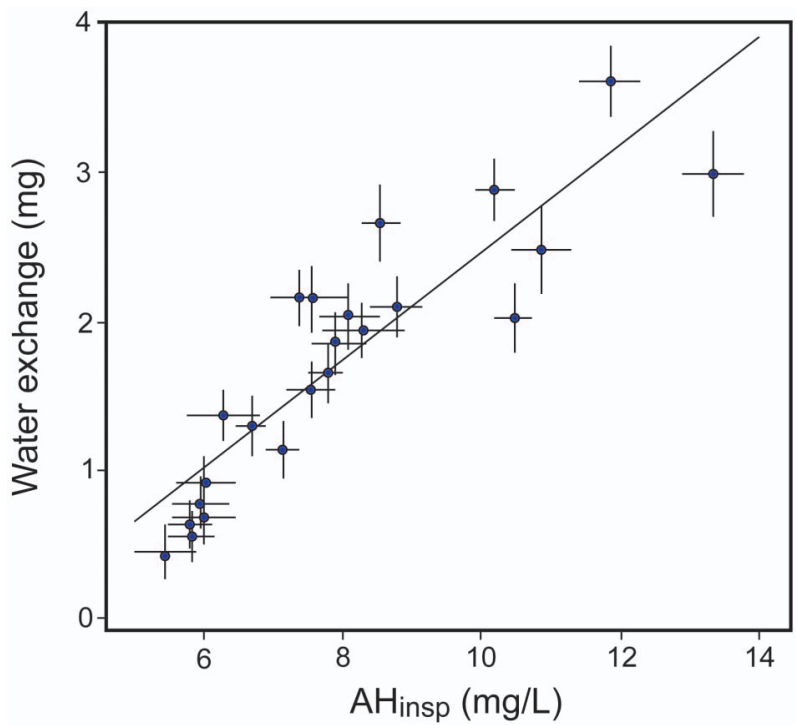

Fig. 4. Correlation between the water exchange and end-inspiratory absolute humidity $\left(\mathrm{AH}_{\text {insp }}\right)$ at a breathing volume of $0.5 \mathrm{~L}$ and normalized to the chosen reference ambient humidity of $5 \mathrm{mg} / \mathrm{L}$. The inverse variance weighted $r^{2}$ is 0.89 . Vertical and horizontal bars represent the standard error per data point.

change capacity (of the $23 \mathrm{HMEs}$ tested) ranged between 0.5 and $3.6 \mathrm{mg}$ at a tidal volume of $0.5 \mathrm{~L}$. Comparison

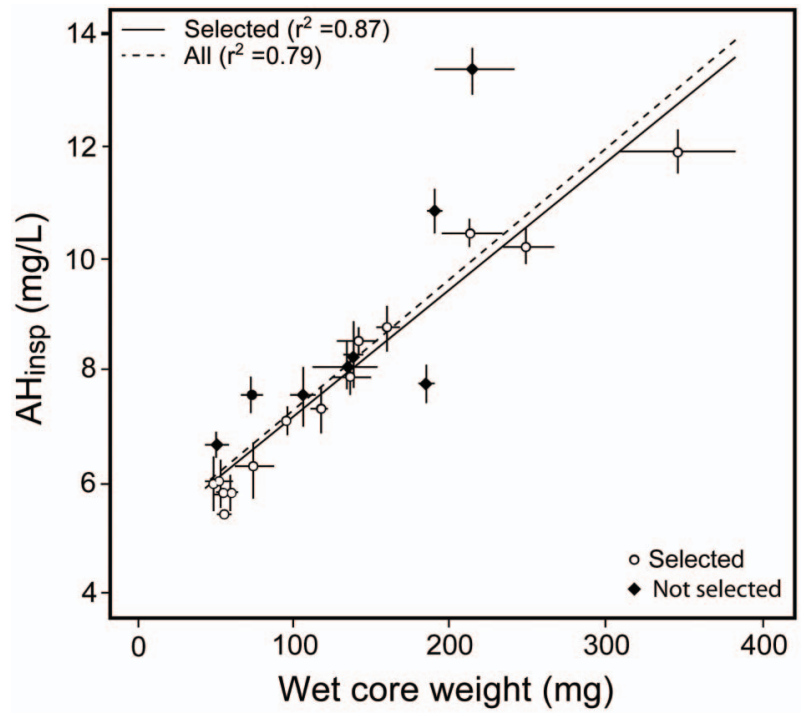

Fig. 5. Relation between wet core weight of the heat and moisture exchanger (HME) and end-inspiratory absolute humidity $\left(\mathrm{AH}_{\text {insp }}\right)$ for all HMEs and for HMEs with a simple cassette (see methods section and Table 1, selected HMEs). The horizontal and vertical bars represent the standard errors of each data point.

studies of other HME types (for temporarily tracheostomized patients and in mechanical ventilation settings) 


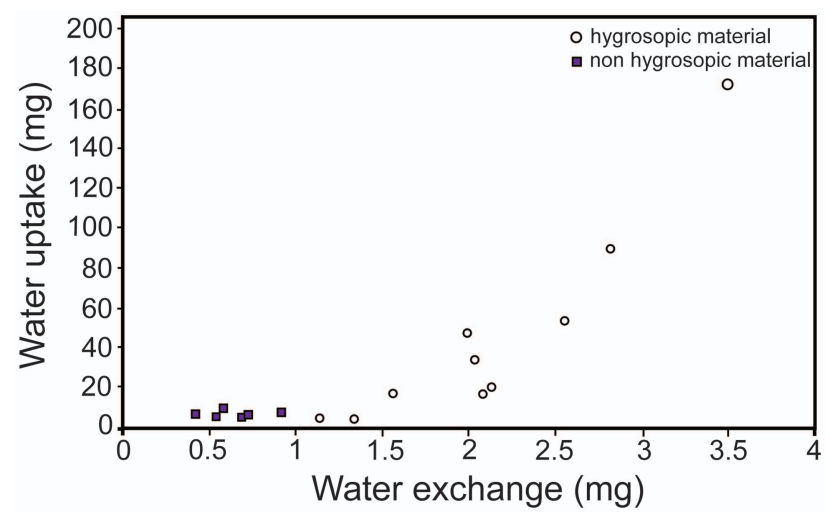

Fig. 6. Water uptake (weight increase between dry and wet heat and moisture exchanger [HME] core material) as function of HME water exchange performance. Not shown are the results from HMEs with a potentially substantial HME effect from the cassette (see methods section and Table 1).

also showed a considerable variability in the performance of HME values. ${ }^{20,26,27}$

The high correlation (Fig. 5, $\mathrm{r}^{2}=0.89$ ) between water exchange and $\mathrm{AH}_{\text {insp }}$ confirms our previous results based on only 6 different HMEs from one manufacturer, which shows that water exchange is a valid measure for HME performance and means a further and broader validation of the ex vivo weighing method. ${ }^{21}$ The present study might have revealed even more interesting results if the manufacturers' ISO specifications for all tested HMEs had been available for comparison with the ex vivo results. Unfortunately, such a comparison was not possible, because the manufacturers approached were unable or unwilling to provide these data, and because the data that were available were measured under different ISO conditions (see Table 1). We have therefore used the $\mathrm{AH}_{\text {insp }}$ as the accepted standard for validation, as this quantity has been validated using in vivo studies against ISO observations, but it is possible that the water exchange actually is a better quantity because it measures the average performance over the full inspiration and expiration, whereas the $\mathrm{AH}_{\text {insp }}$ is only measured at end inspiration (see also Table 5 and Fig. 9 in Appendix 2, available in supplementary materials at http:// www.rcjournal.com). In particular, for the best performing HMEs, the ranking according to the water exchange outcome differs from the ranking according to $\mathrm{AH}_{\text {insp }}$. This might be due to technical difficulties with either of the methods, but it might also be a true result because the water exchange measures the averaged performance over a breathing cycle and $\mathrm{AH}_{\text {insp }}$ is an instantaneous observation.

For 2 Atos Medical HMEs, we found slightly different water exchange values from those reported previously, with notably slightly higher values for the Provox Normal and XtraFlow, resulting in a better correlation with the $\mathrm{AH}_{\text {nsp }}$ (see Table 2). ${ }^{21,28}$ The present results are indeed probably more reliable as a result of a learning curve effect associated with the application of any new technique and, in particular, because we were more careful in this study not to exceed the flow limitation of our spirometer.

The current study has been performed with a mouthbreathing healthy volunteer instead of stoma breathing of a laryngectomized subject. In both situations, the expired air is almost completely saturated with water, but the saturation is more complete in the volunteer $(99 \% \mathrm{RH}$ vs 92\% RH). ${ }^{29,30}$ The use of a laryngectomized patient might have slightly influenced the absolute results, but the relative ordering of the HMEs would not be different, as can also been seen in Figure 7, where the results of this study are compared with actual in vivo observations.

This ex vivo method enables an HME comparison study without performing measurements clinically in laryngectomized patients, which with 23 different HMEs would be a near impossible undertaking. As mentioned in our previous papers, an advantage of the ex vivo HME-weighing method is that it can be carried out by a single volunteer. The reason for this is that the spirometer included in the test configuration registers all breathing variations of the volunteer, so that the inhaled volume-the primary confounder when comparing HMEs - can be taken into account properly and will not be unintentionally influenced by the volunteer. Moreover, in a previous study with 6 different volunteers, the intervolunteer variation was negligible. ${ }^{21}$

This study also provides some additional insight into how HMEs function. Although clinicians might consider it to be a rather simple device (just a piece of foam), the theory of HME performance is actually quite a complicated combination of thermodynamics and flow mechanics. An HME must be able to store (and release) a considerable amount of heat, required to condense and evaporate the water in the expired/inspired air. If the HME is unable to do this, the temperature increase/decrease inside the HME will slow the condensation/evaporation process. ${ }^{31,32}$ The most important parameters of the HME core material are therefore probably heat capacity (to store evaporative heat), its structure (to ensure sufficient contact with the air flowing through the device), and heat conductivity. Heat capacity is determined by the heat capacity index of the chosen material and its quantity. Figure 5 (see also Table 2) shows that the amount of core material predicts HME performance very well for HMEs that do not have an additional HME effect from the cassette (point above the fit line in Fig. 5). Points below the line show core materials that do not participate in the HME effect (dead weight). However, most points are on the fit line, which suggests that all core material participates in the absorption of evaporative heat. The observed ex vivo variations therefore are likely a result of other parameters, such as differences in the heat capacity index of the core material and/or to HME 


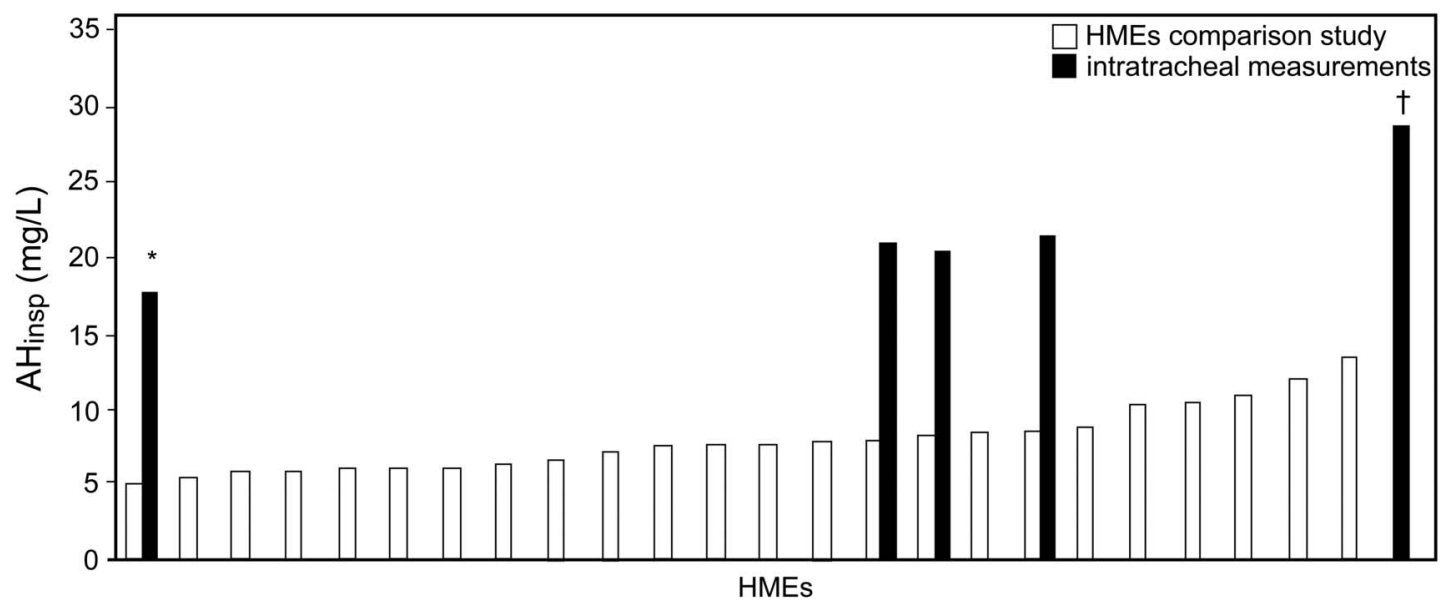

Fig. 7. End-inspiratory absolute humidity $\left(\mathrm{AH}_{\text {insp }}\right)$ of heat and moisture exchangers (HMEs). Filled bars represent the $\mathrm{AH}_{\text {insp }}$ values of $\mathrm{HMEs}$ tested in this study; black bars represent the $\mathrm{AH}_{\text {insp }}$ values of HMEs measured $1 \mathrm{~cm}$ intratracheal in laryngectomized patients for 3 corresponding HMEs and nose breathing. All values are standardized to a reference ambient humidity of $5 \mathrm{mg} / \mathrm{L}$. The intrapatient variability in the intratracheal $\mathrm{AH}_{\text {insp }}$ measurements was large $(2.04 \mathrm{mg} / \mathrm{L})$, due to some variety of the absolute humidity sensor probe in the trachea. ${ }^{14}$ ${ }^{*}$ without $\mathrm{HME},{ }^{\dagger}$ nose breathing.

effects of the cassette. This correlation points toward total heat capacity, determined by the amount of core material, as the most important HME design parameter. HME optimization requires that as much (thin) core material as possible is stored in the limited available space (the HME should stay cosmetically acceptable) without an unacceptable increase in breathing resistance.

This draws attention to the role of hygroscopic salts that are used to improve the performance of some HMEs. The best performing HMEs in this test are hygroscopic HMEs. Two of the HMEs that are supposed to be hygroscopic according to manufacturers' specifications (Servox and Prim-Air Phon I high flow, Table 1) had only an average performance and a weight increase gradient close to zero (Table 2), while showing no water uptake (Fig. 6); these HMEs behave as if they do not contain any hygroscopic salts in/on the core material. The fact that the performance of hygroscopic and nonhygroscopic HMEs with the same wet core weight is comparable also refutes the common notion that hygroscopic salt plays a part in or is required for the quick storage and release of water during breathing. Figure 6 shows the true explanation for the function of hygroscopic salt. It increases the weight of the HME by attracting a layer of water, and, because water has a high heat capacity, the performance of the HME improves. The amount of water can be large; for the Provox XtraMoist HME, for instance, water constitutes $50 \%$ of the total wet core weight.

It is important to note that, although a large water uptake enhances the HME performance, it can also have undesirable side effects. Breathing resistance may increase if the pores in the foam become too small, and, in extreme cases (such as entering very cold outside air from a warm room), excessive water might condense in the HME and may start dripping into the trachea or on the clothes/skin.

To understand the meaning of these ex vivo results for clinical practice, the issue is to what extent these HMEs can bridge the physiological humidity gap between nose and stoma breathing. ${ }^{13,30,33-35}$ The physiological tracheal climate during nose breathing is known for healthy volunteers and for head and neck cancer patients with a temporary tracheotomy. ${ }^{29,30}$ As laryngectomized patients are head and neck cancer patients, the subglottic humidity value during nose breathing in this patient group $(29.3 \mathrm{mg} / \mathrm{L}$ at $1 \mathrm{~cm}$ behind the temporary tracheostoma) $)^{30}$ can be considered the target humidity value in the upper trachea of laryngectomized patients. In Figure 8 (available in the supplementary materials at http://www.rcjournal.com), the HMEs tested are placed in order of their $\mathrm{AH}_{\text {insp }}$ values next to the target $\mathrm{AH}_{\text {insp }}$ value of nose breathing (all values are standardized to a reference ambient humidity of $5 \mathrm{mg} / \mathrm{L}$ ). Also included in the figure are the considerably higher in vivo values of three HMEs published previously.12,22 These are due to the fact that the trachea itself has a considerable HME effect too, which influences the in vivo measurements where the humidity is measured in the stoma/trachea approximately $1 \mathrm{~cm}$ behind the HME. This effect is absent in the ex vivo setup, where the absolute humidity sensor was placed downstream of the HME outside the body. Extrapolating the trend of the in vivo values to those of the ex vivo measurements, as shown in Figure 7 , one can see that the best performing HMEs come closer to the target value for optimal physiological climate conditions in the trachea. However, there is clearly still some room for improvement of the water exchange capacity even with the best performing HMEs. 


\section{Assessment of HMEs for Patients With LaRyngectomy}

The better understanding of HME performance achieved in the present study should help professionals in choosing the right HME for their patients. It might furthermore trigger the development of new HMEs for laryngectomized patients with performance that restores the physiological situation in the trachea even more, leading to an even greater reduction of clinical complaints and improvement of laryngectomized patients' quality of life.

\section{Conclusions}

The 23 HMEs for laryngectomized patients tested show wide variation in water exchange performance. Water exchange correlates well with the end-inspiratory absolute humidity outcome, which validates the ex vivo weight change method. In addition, (wet) core weight is a good predictor of HME performance for HMEs with a simple cassette. Hygroscopic salt increases the weight of the core material and therefore the performance of the HME. The results of this study can help medical professionals to obtain a more founded opinion about the performance of available HMEs for pulmonary rehabilitation in laryngectomized patients, and allow them to make an informed decision on which HME type to use.

\section{ACKNOWLEDGMENTS}

We acknowledge Klaus Züchner $\mathrm{PhD}$ for providing the heated capacitive hygrometer. ${ }^{23}$

\section{REFERENCES}

1. Hilgers FJ, Ackerstaff AH, Aaronson NK, Schouwenburg PF, van Zandwijk N. Physical and psychosocial consequences of total laryngectomy. Clin Otolaryngol Allied Sci 1990;15(5):421-425.

2. Ackerstaff AH, Hilgers FJ, Aaronson NK, Balm AJ, van Zandwijk $\mathrm{N}$. Improvements in respiratory and psychosocial functioning following total laryngectomy by the use of a heat and moisture exchanger. Ann Otol Rhinol Laryngol 1993;102(11):878-883.

3. Hilgers FJ, Aaronson NK, Ackerstaff AH, Schouwenburg PF, van Zandwikj N. The influence of a heat and moisture exchanger (HME) on the respiratory symptoms after total laryngectomy. Clin Otolaryngol Allied Sci 1991;16(2):152-156.

4. Ackerstaff AH, Hilgers FJ, Balm AJ, Tan IB. Long-term compliance of laryngectomized patients with a specialized pulmonary rehabilitation device: Provox Stomafilter. Laryngoscope 1998;108(2):257260.

5. Bieñ S, Okła S, van As-Brooks CJ, Ackerstaff AH. The effect of a Heat and Moisture Exchanger (Provox HME) on pulmonary protection after total laryngectomy: a randomized controlled study. Eur Arch Otorhinolaryngol 2010;267(3):429-435.

6. Dupuis P, Guertin L, Rainville MS, Prud'homme DL, Lavigne F. Montreal's experience with Cyranose heat and moisture exchanger use in 15 laryngectomized patients. J Otolaryngol 2007;36(4):208212.

7. Jones AS, Young PE, Hanafi ZB, Makura ZG, Fenton JE, Hughes JP. A study of the effect of a resistive heat moisture exchanger (Trachinaze) on pulmonary function and blood gas tensions in patients who have undergone a laryngectomy: a randomized control trial of 50 patients studied over a 6-month period. Head Neck 2003; 25(5):361-367.

8. Moerman M, Lawson G, Andry G, Remacle M. The Belgian experience with the Cyranose heat moisture exchange filter: a multicentric pilot study of 12 total laryngectomees. Eur Arch Otorhinolaryngol 2003;260(6):301-303.

9. Herranz J, Espiño MA, Morado CO. Pulmonary rehabilitation after total laryngectomy: a randomized cross-over clinical trial comparing two different heat and moisture exchangers (HMEs). Eur Arch Otorhinolaryngol 2013;270(9):2479-2484.

10. McRae D, Young P, Hamilton J, Jones A. Raising airway resistance in laryngectomees increases tissue oxygen saturation. Clin Otolaryngol Allied Sci 1996;21(4):366-368.

11. Zuur JK, Muller SH, Sinaasappel M, Hart GA, van Zandwijk N, Hilgers FJ. Influence of heat and moisture exchanger respiratory load on transcutaneous oxygenation in laryngectomized individuals: a randomized crossover study. Head Neck 2007;29(12):1102-1110.

12. Scheenstra RJ, Muller SH, Vincent A, Sinaasappel M, Hilgers FJ. Influence of breathing resistance of heat and moisture exchangers on tracheal climate and breathing pattern in laryngectomized individuals. Head Neck 2010;32(8):1069-1078.

13. Keck T, Dürr J, Leiacker R, Rettinger G, Rozsasi A. Tracheal climate in laryngectomees after use of a heat and moisture exchanger. Laryngoscope 2005;115(3):534-537.

14. Scheenstra RJ, Muller SH, Vincent A, Sinaasappel M, Zuur JK, Hilgers FJ. Endotracheal temperature and humidity measurements in laryngectomized patients: intra- and inter-patient variability. Med Biol Eng Comput 2009;47(7):773-782.

15. Zuur JK, Muller SH, de Jongh FH, van der Horst MJ, Shehata M, van Leeuwen J, et al. A newly developed tool for intra-tracheal temperature and humidity assessment in laryngectomized individuals: the Airway Climate Explorer (ACE). Med Biol Eng Comput 2007;45(8): 737-745.

16. Wilkes AR. The moisture-conserving performance of breathing system filters in use with simulated circle anaesthesia breathing systems. Anaesthesia 2004;59(3):271-277.

17. Grolman W, Blom ED, Branson RD, Schouwenburg PF, Hamaker RC. An efficiency comparison of four heat and moisture exchangers used in the laryngectomized patient. Laryngoscope 1997;107(6):814820 .

18. International Standards Organization. Anaesthetic and respiratory equipment: heat and moisture exchangers (HMEs) for humidifying respired gases in humans; Part 1: HMEs for use with minimal tidal volume of $250 \mathrm{~mL}$ (ISO 9360-1:2000) http://www.iso.org/iso/ catalogue_detail.htm?csnumber=23913. Accessed July 14, 2014.

19. International Standards Organization. Anaesthetic and respiratory equipment: heat and moisture exchangers (HMEs) for humidifying respired gases in humans; Part 1: HMEs for use with tracheostomized patients having minimal tidal volume of $250 \mathrm{~mL}$ (ISO 9360-2:2001) http://www.iso.org/iso/home/store/catalogue_tc/catalogue_detail. htm?csnumber $=30137$. Accessed July 14, 2014.

20. Chikata Y, Oto J, Onodera M, Nishimura M. Humidification performance of humidifying devices for tracheostomized patients with spontaneous breathing: a bench study. Respir Care 2013;58(9):1442-1448.

21. van den Boer C, Muller SH, Vincent AD, Züchner K, van den Brekel MW, Hilgers FJ. A novel, simplified ex vivo method for measuring water exchange performance of heat and moisture exchangers for tracheostomy application. Respir Care 2013;58(9):1449-1458.

22. Scheenstra RJ, Muller SH, Vincent A, Ackerstaff AH, Jacobi I, Hilgers FJ. Short-term endotracheal climate changes and clinical effects of a heat and moisture exchanger with an integrated electrostatic virus and bacterial filter developed for laryngectomized individuals. Acta Otolaryngol 2010;130(6):739-746. 


\section{Assessment of HMEs for Patients With LaRyngectomy}

23. Rathgeber J, Kahle G, Schulze T, Zuchner K. Rapid measurement of water vapor partial pressure at the saturation point with a new hybrid humidity sensor. Biomed Tech (Berl) 2000;45(10):288-292.

24. Ploysongsang Y, Branson R, Rashkin MC, Hurst JM. Pressure flow characteristics of commonly used heat-moisture exchangers. Am Rev Respir Dis 1988;138(3):675-678.

25. Dow Chemical. The calcium chloride handbook: a guide to properties, forms, storage and handling. http://www.prog-univers.com/IMG/ pdf/CalciumChloridHandbook.pdf. Accessed June 23, 2014.

26. Lellouche F, Taillé S, Lefrançois F, Deye N, Maggiore SM, Jouvet $\mathrm{P}$, et al. Humidification performance of 48 passive airway humidifiers: comparison with manufacturer data. Chest 2009;135(2):276286.

27. Esquinas AM, BaHammam AS. Humidification during noninvasive ventilation in the critically ill. Respir Care 2013;58(3):e35-e36.

28. van den Boer C, Muller SH, Vincent AD, Züchner K, van den Brekel MW, Hilgers FJ. Ex vivo water exchange performance and shortterm clinical feasibility assessment of newly developed heat and moisture exchangers for pulmonary rehabilitation after total laryngectomy. Eur Arch Otorhinolaryngol 2014;271(2):359-366.
29. Ingelstedt S. Studies on the conditioning of air in the respiratory tract. Acta Otolaryngol Suppl 1956;131:1-80.

30. Scheenstra RJ, Muller SH, Vincent A, Hilgers FJ. Heat and moisture exchange capacity of the upper respiratory tract and the effect of tracheotomy breathing on endotracheal climate. Head Neck 2011; 33(1):117-124.

31. Revenäs B, Lindholm CE. Temperature variations in disposable heat and moisture exchangers. Acta Anaesthesiol Scand 1980;24(3):237240

32. Shelly M, Bethune DW, Latimer RD. A comparison of five heat and moisture exchangers. Anaesthesia 1986;41(5):527-532.

33. Ingelstedt S. Humidifying capacity of the nose. Ann Otol Rhinol Laryngol 1970;79(3):475-480.

34. McRae RD, Jones AS, Young P, Hamilton J. Resistance, humidity and temperature of the tracheal airway. Clin Otolaryngol Allied Sci 1995;20(4):355-356

35. Zuur JK, Muller SH, Vincent A, Sinaasappel M, de Jongh FH, Hilgers FJ. Assessment of tracheal temperature and humidity in laryngectomized individuals and the influence of a heat and moisture exchanger on tracheal climate. Head Neck 2008;30(8):1072-1082.

This article is approved for Continuing Respiratory Care Education credit. For information and to obtain your CRCE

(free to AARC members) visit www.rcjournal.com

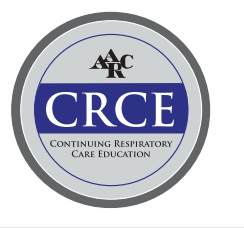

